Specimen No. 38 shows a distinct difference from the ones just preceding and following, indicating that this steel has a narrow range of temperature in which it can be treated with the best results. This specimen shows the clearest and cleanest structure and is microscopically the best specimen of the group.

In the reproduction of one of the photographs from specimen No. 33 is shown a case referred to in paragraph No. 24. It illustrates the cracking of a specimen which has been heated too rapidly, and quenched before the heat had been allowed to uniformly penetrate to the center of it. However, it does appear remarkable that this specimen did not break under the physical test.

The illustrations from photographs of the fractures show the increase in size of grain as in the preceding series.



No. 38 .

Red Hardness as Affected by the Structure of the Steel. - The property named red hardness in a highspeed tool steel, and which enables it to cut metal when the cutting edge and near portions are heated to a dull red, should, to a certain extent, be related to the structure of the steel according to the above statements.

The heat which is generated by friction between the steel crystals (these being caused to move by vibration) does not destroy the tool as rapidly as the grinding on the crystals by the separated hard constituents, which are present at some temperatures. As the structure of the steel in this case generally consists of crystals of an uneven size, the smaller ones of these are ground to pieces in a comparatively short time, and the cutting edge of the tool is ruined.

Therefore, a uniform size of crystals without separated hard constituents between them in the structure of the tool steel will give a large amount of red hardness or high durability, considering the structure of the steel only and apart from the various effects of the chip upon the tool in cutting metals.
To find the element, or combination of elements, in the steel responsible for the highest durability, requires the most elaborate experimenting, in the making of the steel, the heat treatments, and the physical tests, and is beyond the object of the experiments described in this paper. However, it is seen that two slightly different chemical compositions of the steel, subjected to the same heat treatment, show a great difference in durability.

Taking the results of these experiments as a whole, the general shop rule for treating a high-speed tool"Heat it to a white heat and quench it"- does have its shortcomings, because a variation of $50^{\circ} \mathrm{F}$. cannot be determined by the eye.

What are the results of a poorly treated tool? It decreases the shop production for the manufacturer, who allows it inside his establishment.



It increases the bill of the customer, wlo pays for the tool and the work spent on it.

When the works manager comes through the shop and inquires about the tools, the workman naturally testifies the tool steel to be of inferior quality, which, as we have seen, may not be the case, but this tool steel maker has to find a new market for his stock of steel.

In short, it is waste of energy and waste of capital.

\section{APPLICATION OF ELECTROSTATIC SEPARATION TO ORE DRESSING.}

By F. S. MacGregor.

The possibility of utilizing the differences in the electrical conductivity of various minerals by giving a part or all of the particles of ore an electrostatic charge has for several years been recognized as a means of separation, and a large amount of experimenting has been done along this line. The com-

1 A paper presented at the Eighteenth General Meeting of the Axnerican Electrochemical Society, in Chicago, October 13-15, 1910 , 
mercial application of the art of electrostatic separation has been tried a number of times within the last decade, but until only within about three years has success attended the efforts.

Two factors contributed to this want of successa lack of the proper means of continuous electrification and a practical machine and system of treatment designed to meet the rigorous requirements of mill operation. Recognizing these conditions, the Huff Electrostatic Separator Company, of Boston, has perfected several types of separators and a means of electrification which have been a commercial success from their first installation, and at present the entire concentrating and separating machinery of two plants consists of Huff separators-one located at Platte- the ore across the first electrode, and it passes by gravity to each succeeding one. The mineral. particles receive their charge while passing through a concentrated static field formed by two electrodes-one a grounded rotated shaft, and the other an insulated metal rod. The electrostatic charging of the electrodes is accomplished by a special e'ectrical apparatus (using commercial dynamos and transformers), which, with no more than the usual oiling, gives either a continuous and steady potential of several thousand volts, or an intermittent or pulsating charge of great regularity. The potential, or strength of the field, can be altered at will, according to the conductivities of various ores treated. The figure shows the scheme of separation, the dotted lines

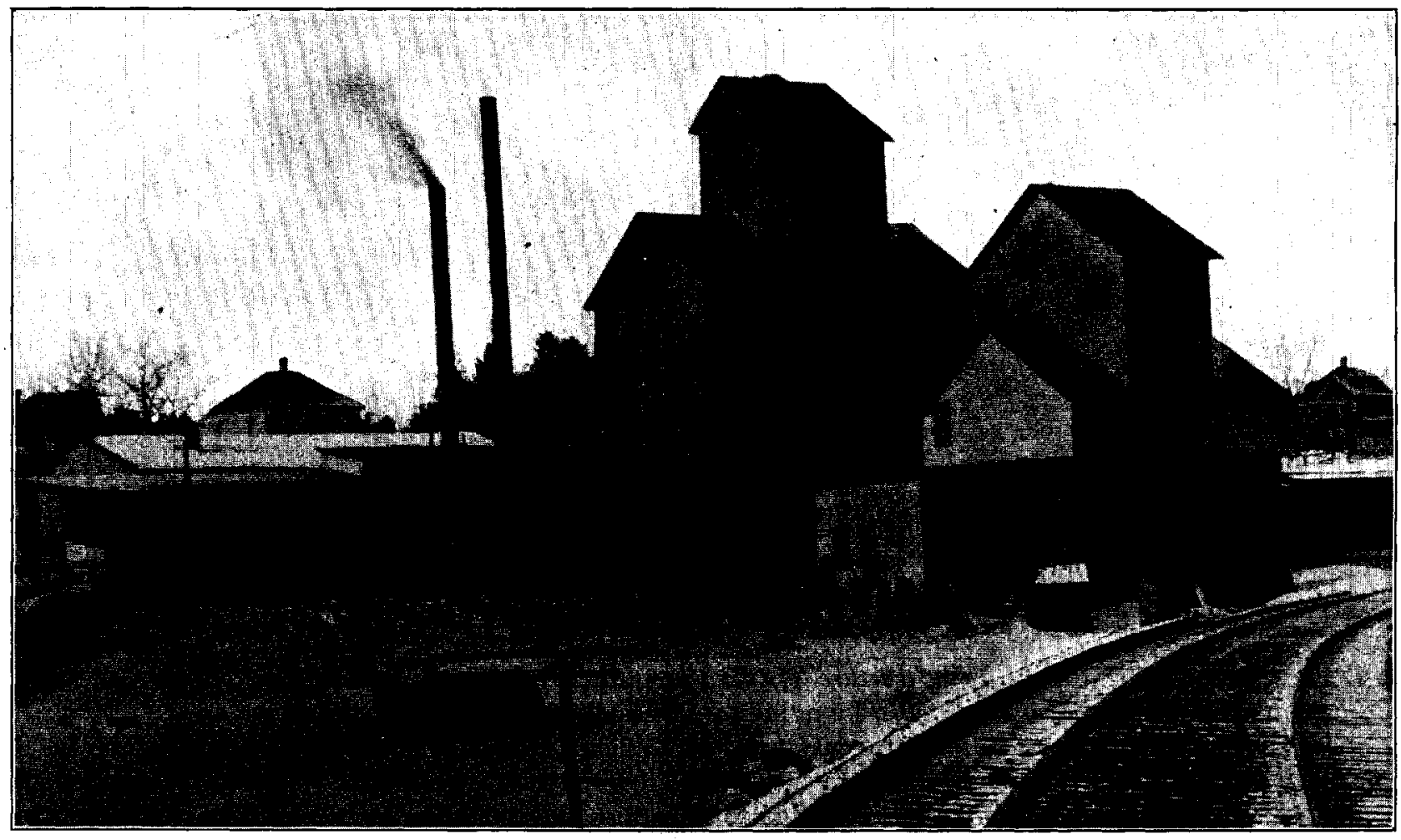

Fig. 1.-Electrostatic separating plant, American Zinc Ore Separating Co., Platteville, Wis.

ville, Wisconsin, owned by the American Zinc, Lead and Smelting Company," and the other at Midvale, Utah, owned by the United States Smelting, Refining and Mining Company. Also a plant is being installed in Nevada.

The type of machine is shown in the accompanying illustration, and consists of a series of separating electrodes placed one above the other. The frame is cast-iron, built in sections, with two electrodes to each section, which facilitates easy shipment and also flexibility in the number of treatments which can be given the ore, and which is dependent on its requirements. A three-section machine (the usual type) is six feet high, six feet six inches long, and eighteen inches wide. A feed hopper on the top distributes indicating in general the path of the conductors and non-conductors.

The separating plant at Platteville was started in March, 1908, and was the first plant to be equipped with Huff separators. Although originally built as an experimental plant, it has been in practically continuous operation since then, and used to separate, without roasting, the iron pyrite from the zinc blende, which occur together in varying proportions in southwestern Wisconsin. The ores are milled in ordinary jigs and the lead and lime rock removed. Owing to the nearness in specific gravity of the blende and pyrite, they are recovered in the jigs as a middlings, containing from ro to 45 per cent. zinc, according to the grade of the crude ore, the remaining percentage be- 
ing iron and the sulphur in combination. Iron above a few per cent. interferes with the smelting of the blende, and the function of this plant is to remove this pyrite, making the low-grade ores into highgrade smelting ores.

The plant consists of a wooden, frame building, 9 $x$ I 2 meters $(30 \times 40$ feet), and three stories high. On the first floor are the bins for collecting the finished products as they are delivered from the separators. The second and third floors are separator floors, and in the tower is located the screening system. A spur railroad track runs on either side of the mill, one for cars of raw ore, allowing them to be unloaded either directly into the mill or into storage bins across the track. The other track, which is below the mill level, permits at the same time the loading of empty cars with finished products.

The course of the ore through the plant is shown
There are four, giving an oversize and four other sizes, called A, B, C and D. In general, the sizes are as follows:

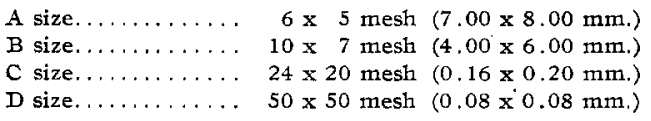

The oversize passes through a short trommel to remove any foreign materials, and is spouted to the first floor to a set of rolls, which crush it and deliver it to the boot of the elevator carrying the original feed.

The location of the screens in a tower permits the different sizes to flow by gravity through iron pipe 5 $\mathrm{cm}$. (2 inches) in diameter to the top machine floor. On this floor are located the rougher machines, where the ore is given a rough split, that is, two products are made, one a product higher in zinc than the original feed, and the other higher in iron. Thus, no matter what the grade of the feed to the mill may

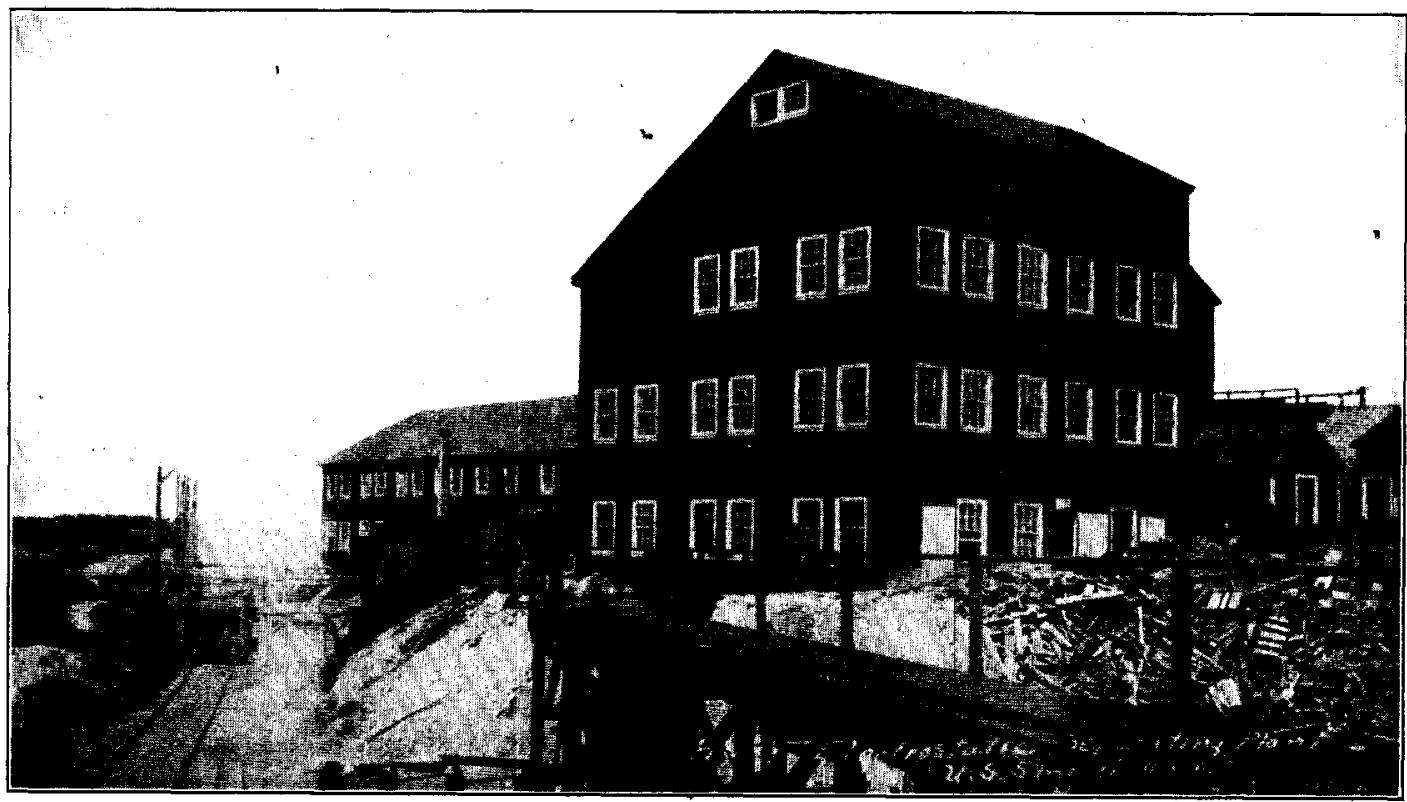

Fig. 2.-Electrostatic separating plant, showing loading trestle, U. S. Smelting Co., Midvale, Utah.

in the flow sheet, and may be described in detail as follows: It is shoveled into a wheelbarrow in the freight car, wheeled to scales and weighed, then dumped into the feed hopper of the drier. The top of this hopper is on a level with the car floors to facilitate easy handling of the ore, and at the bottom of this hopper is an adjustable plunger feeder. The drier is of the cylindrical type, and the shell is 5 meters ( 16 feet) long and 0.75 meter (30 inches) in diameter, rotating about $4 \frac{1}{2}$ r. p. m. Being set at a slight pitch, the ore travels gradually to the discharge end, where it emerges bone-dry. As the separation depends on the difference in conductivity of the minerals, it is necessary that all moisture be removed.

A short drag conveyor carries the dried ore to the foot of a bucket elevator, which raises it to the top of the tower and discharges it into a set of screens. be (and it varies within wide limits), a fairly uniform mixture is sent to the finishing machines on the floor below.

These finishing machines give the final cleaning to the ore, one set giving a finished iron product and the other a finished zinc product. The middlings from these cleaners return by gravity to the boot of the elevator and mix with the fresh ore, so that no ore leaves the system that is not separated into its proper grades of product.

The finished zinc product and finished iron product fall into separate bins on the first floor. These bins are $\mathrm{V}$-bottomed, and constructed of two thicknesses of wood flooring with heavy building paper between. They are elevated from the floor so that they may conveniently be drawn off into a $730 \mathrm{~kg}$. ( $1,600 \mathrm{lb}$.) capacity push car for loading. 
The car is then wheeled to a small elevator and dumped into a hopper on the floor level. This feeds the ore into the boot of a small elevator, which discharges either into a freight car by means of a gooseneck spout, or may be allowed to discharge to a second

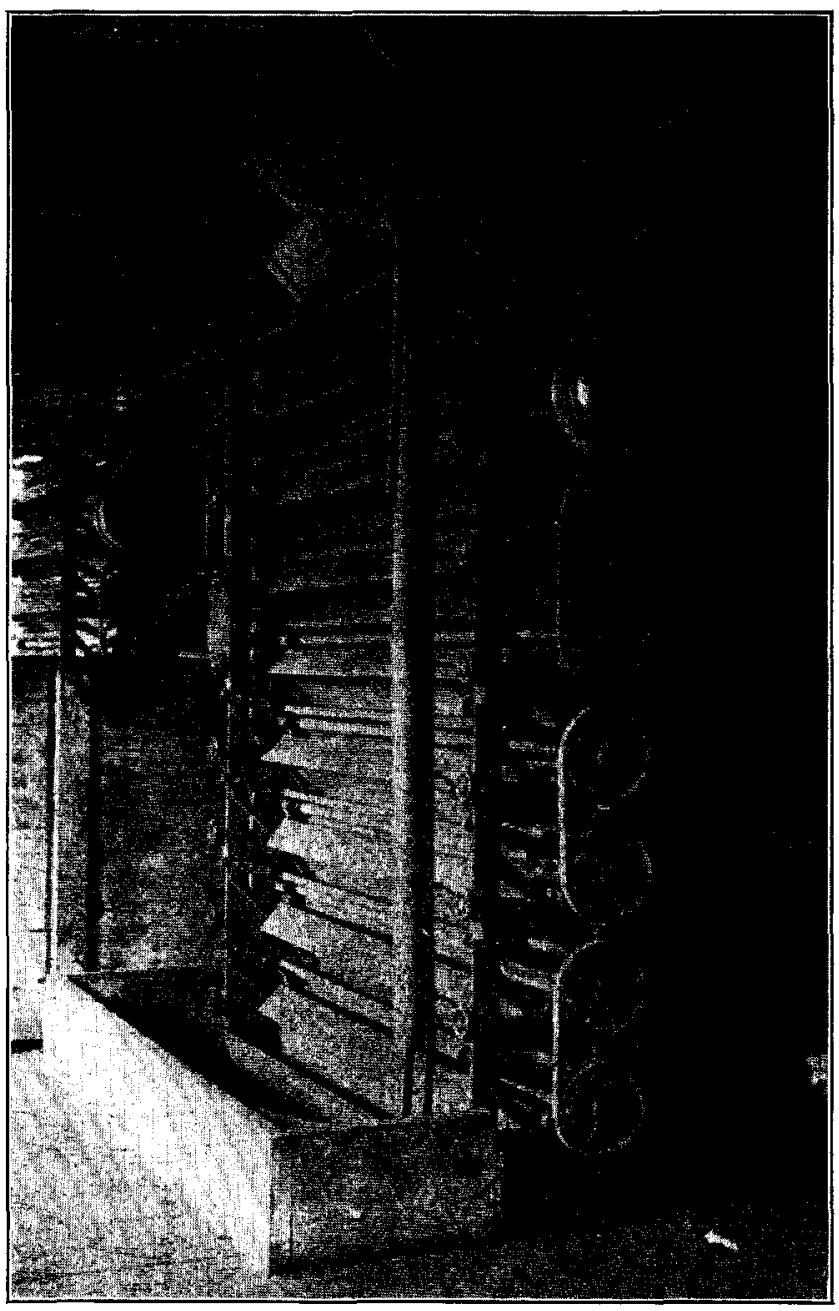

Fig. 3.-Huff electrostatic separator.

elevator in the storage bins. From these bins a car may be loaded whenever convenient.

The plant generates its own power, and the engine and boiler rooms are located in an adjoining building. The fire boxes of the boiler and drier are side by side, enabling the engineer to look after both fires as well as the engine room. Power is supplied by a Corliss engine, connected to the mill by a clutch.

The plant operates continuously three shifts per day. The labor required per twenty-four hours is as follows:

$$
\begin{aligned}
& 3 \text { shift bosses ( } 8 \text { hours each). } \\
& 3 \text { machine helpers ( } 8 \text { hours each). } \\
& 3 \text { drier feeders ( } 8 \text { hours each). } \\
& 2 \text { loaders ( } 10 \text { hours each). } \\
& 2 \text { engineers ( } 13 \text { and } 11 \text { hours each). }
\end{aligned}
$$

There is also a superintendent, master mechanic, assayer, one buyer and bookkeeper, although the buyer and, to a large extent, the assayer devote their time to obtaining custom work.
Two products of marketable value are obtained: The iron pyrite, hitherto valueless in these Wisconsin ores, is sold for its sulphur content, and by reason of its free-burning qualities, makes a very desirable product for the acid manufacturer; and a zinc product, which is, of course, sold for spelter. The pyrite is sold by contract, but the blende is sold to the smelters on the open market. With a penalty for excess of iron or lead, one may see it is necessary for such a plant to turn out consistently high-grade products in order to command a satisfactory market price.

The results taken from the "Record of Shipments" for a month show an average zinc product of 55.2 per cent. $\mathrm{Zn}$ and 3.4 per cent. Fe, and a pyrite product of 3.7 per cent. $\mathrm{Zn}$ and 44.7 per cent. S. The average zinc content of the ore bought and separated into the above products was 24 . I per cent. $Z \mathrm{n}$, and the average iron content was 25.4 per cent. Fe. The minimum zinc content was 6.7 per cent. $\mathrm{Zn}$, and the maximum $4 \mathbf{I} .2$ per cent. $Z n$. The high grade of the separated products shows the flexibility of the process and the ability of the plant to handle any grade of ore from the district.

As a result of the excellent showing of this electrostatic plant, the United States Smelting, Mining and Refining Company decided to put in a plant at their works at Midvale, Utah. The function of an electrostatic plant there is different from that in Platteville, for the ore from the mine of the United States Company, at Bingham, Utah, contains about 9 per cent. of zinc in addition to the gold, silver and lead values.

This ore is shipped to the concentrator at Midvale, where it is crushed and milled by the usual methods of jigs and tables. In this concentration there were formerly two products, one a lead-pyrite product carrying the iron and considerable zinc, and a tailings carrying zinc and some gold and silver values, the object being to keep the zinc as low as possible in the

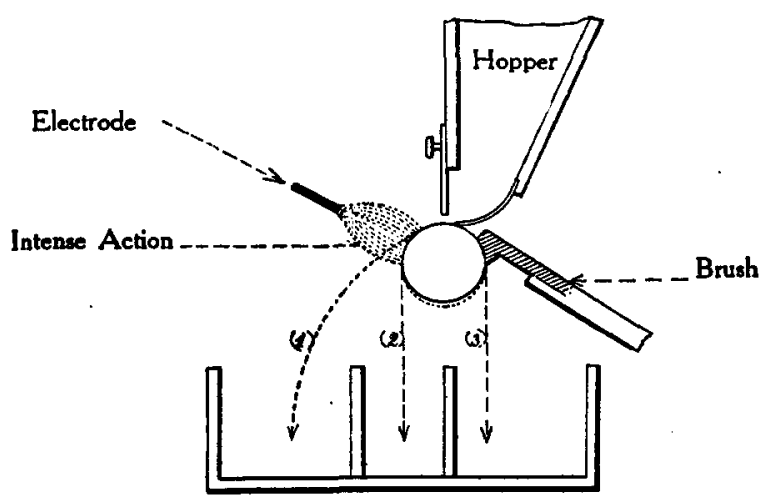

Fig. 4,-Section of electrostatic separator, showing principle of operation.

lead concentrate, and yet at the same time make the maximum recovery of the gold, silver, lead and copper values. The zinc added materially to the 
difficulty and cost of smelting the lead concentrates, and, at the same time, was a total loss. In order to recover this zinc, three products were made in the concentrator, a lead-pyrite carrying practically no

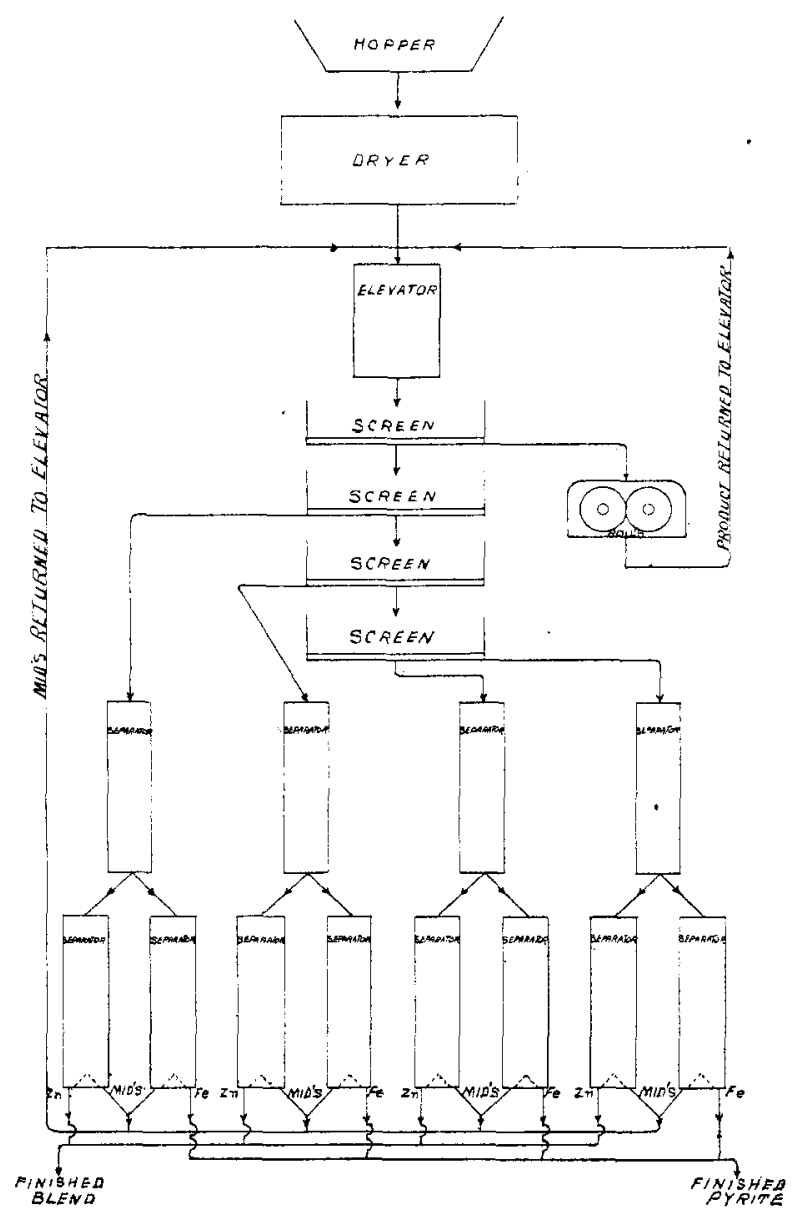

Fig. 5.-Flow-sheet, showing course of ore through the mill.

zinc, tailings free from zinc, and middlings containing about 22 per cent. zinc, the balance pyrite and some copper, lead, gold and silver.

To treat these middlings, an electrostatic plant was built near the concentrator as shown. It is a wooden frame building I $2 \times \mathrm{I} 2$ meters ( $40 \times 40$ feet) and covered with corrugated sheet-iron. In general plan it is the same as the Platteville plant-finished ore bins on the ground floors, and two floors of separators. The method of handling the ore is somewhat different. The middlings are shoveled from the table hutches in the wet concentrator into tramcars, which are pushed by hand to the platform elevator at the electrostatic plant. The cars are raised to the third floor level, and, after weighing, are dumped into a 40-ton hopper. This is built over the drier, and feeds automatically. After drying, the ore is screened as follows, making A size 12 on $24, B$ size 24 on $50, C$ size through 5o-mesh.

The oversize is small in amount and very low in zinc, so instead of recrushing, it is put directly into the finished pyrite. The three sizes, A, B and C, are separated, and the products drawn from the bins on the first floor into tramcars. These are run out of the mill to the loading trestle and dumped into freight cars. The pyrite product is smelted in the United States smelter near-by, and the zinc product shipped to the Kansas zinc smelters.

The plant is electric-driven by a $20 \mathrm{~h}$. p. motor, the ${ }_{5} \mathrm{Huff}$ separators requiring about $1 / 3 \mathrm{~h}$. p. each. The generating apparatus for the electrostatic field is located in, a small room on the finishing floor. A 3 h. p. motor is direct coupled to a generator, and the strength of field is controlled from a small switchboard. The plant is operated in conjunction with the concentrator, and the superintendence, assaying and bookkeeping are taken care of by the smelter staff.

The average assays of the feed and products are as follows:

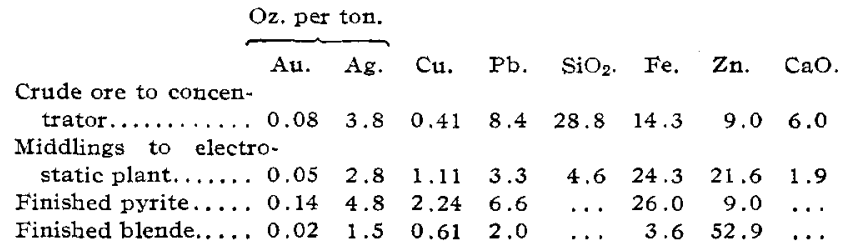

This electrostatic plant not only removes the objectionable zinc from the lead-pyrite concentrate, but makes of it a marketable product, and; instead of being a total loss, it is made to produce a profit. The electrostatic process in these two plants demonstrates two applications in ore dressing, one the custom plant making low-grade ores profitable, and the other as an adjunct to a wet concentrator for the recovery of zinc.

Besides these plants, there is being installed in Nevada a plant working on crude silver ores, wherein the ore goes through no concentrating machinery prior to its electrostatic treatment. The process has been proved applicable to many special problems such as the concentration of copper and lead-silver ores in

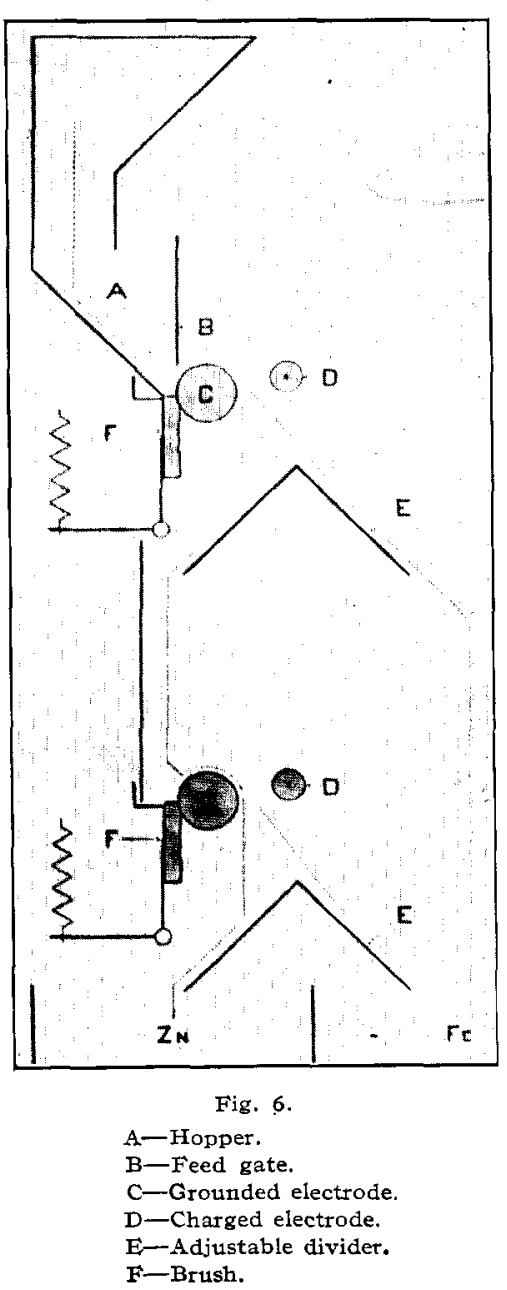




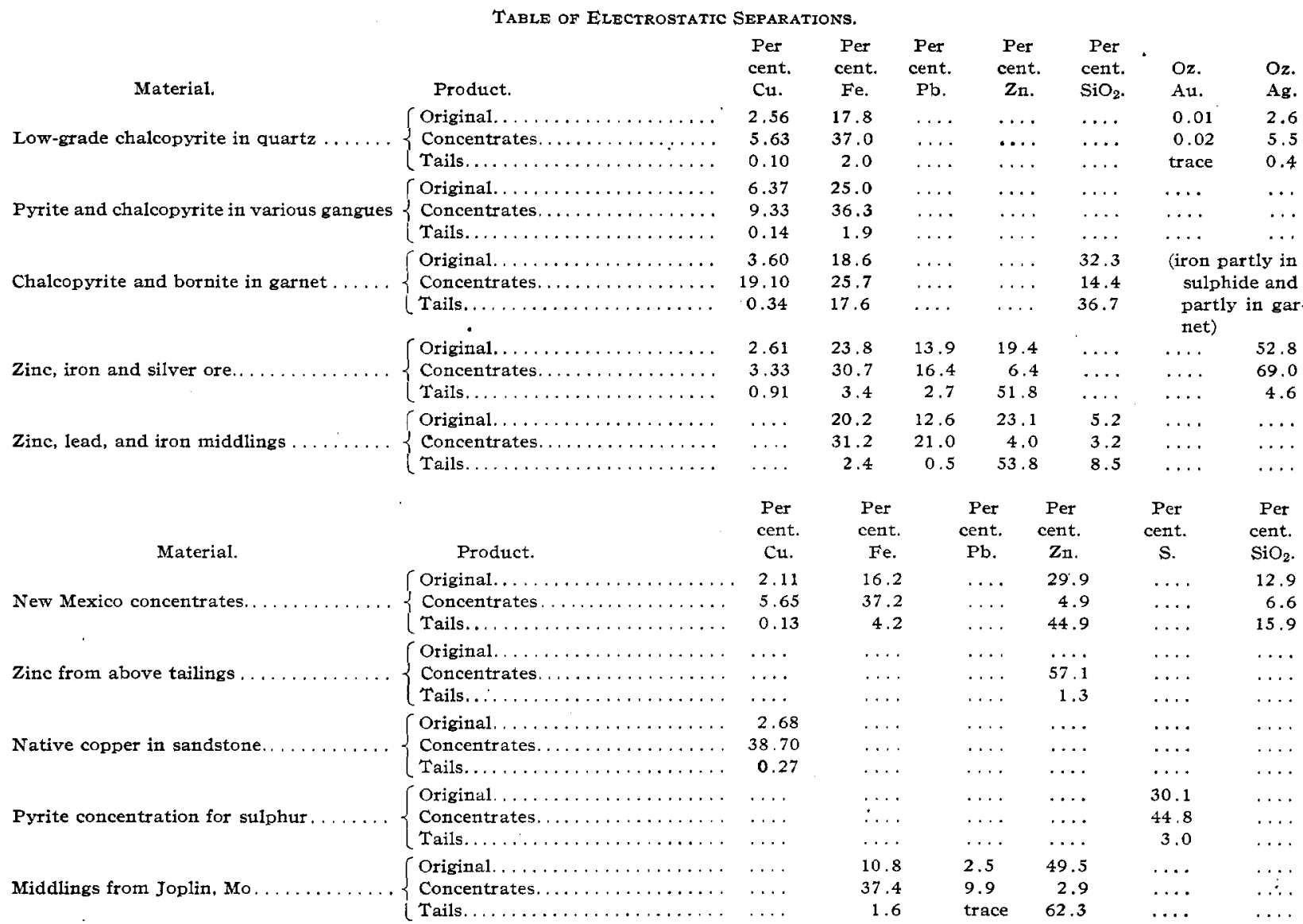

heavy gangues such as garnet, barite, epidote, etc. The accompanying table will give some idea of what can be expected with several of these problems.

The perfection of the art of electrostatic separation marks an important step in the dressing of complex or difficultly milled ores.

\section{EFFICIENCY IN THE ELECTROLYTIC PRODUC- TION OF METALLIC CALCIUM. ${ }^{1}$}

By Francis C. Frary, Henry R. Bicknell and Carl A. Tronson. Received October 12, 1910.

Most of those who have worked on the electrolytic production of calcium have been content to describe their methods and apparatus, with perhaps an analysis of a selected lump of their product, but say nothing of the current efficiency obtained. Muthmann, ${ }^{2}$ in the discussion of a paper by Rathenau, states that by using an electrolyte consisting of two parts of calcium chloride to one part of the fluoride, and raising the iron cathode as the metal accumulated, he obtained a "good" yield. Goodwin, ${ }^{3}$ electrolyzing pure calcium chloride in a similar way, obtained a

1 A paper presented at the Eighteenth General Meeting of the American Electrochemical Society, in Chicago, October 13-15, 1910. The work described in this paper is a continuation of that published by Frary and Badger (Trans. Am. Electrochem. Soc., 16, 185) where a summary and discussion of previous work on the electrolytic production of calcium will be found.

2 Z. Elektrochem., 10, 508 (1904).

${ }^{3} \mathrm{~J}$. Am. Chem. Soc., 27, 1403 (1905). current efficiency of 2 I.5 per cent. to 4 I. 9 per cent. Woehler, ${ }^{1}$ using an electrolyte containing roo parts of the chloride to 17 parts of the fluoride, claims an efficiency of over 80 per cent., but states that the electrolyte deteriorated in time, probably owing to the formation of the hydrated oxychloride, and that hydrogen (!) is then liberated at the cathode, and the yield decreases. He used a current of 40 amperes at 33 to 38 volts, but does not say how often or for how long a time this efficiency could be obtained. Tucker and Whitney ${ }^{2}$ improved the apparatus of Goodwin, and claim an efficiency of 60 per cent., using the pure chloride as electrolyte, but give no data to support the claim. As far as we are able to ascertain, no one else has published any results on the efficiency of the various processes which have been proposed.

During previous work in this laboratory, ${ }^{3}$ efficiencies as high as 46 per cent. were obtained, but, unfortunately, the only runs in which the necessary data were taken were made under unfavorable conditions. As it was certain that better results could be obtained and had been obtained in some of the runs for which no data were at hand, these were not published at the time, and the work was continued by the present authors.

\footnotetext{
1 Z. Elektrochem., 11, 612 (1905).

2 J. Am. Chem. Soc., 28, 84 (1906).

3 Frary and Badger, Loc. cit.
} 